\title{
Resveratrol and Colorectal Cancer: Focus In vitro, In vivo and Clinical Assays
}

\author{
Paolo Ruggero Errante* and Afonso Caricati Neto \\ Associate Researcher, Laboratory of Autonomic and Cardiovascular Pharmacology, Department of Pharmacology, UNIFESP, \\ São Paulo, Brazil.
}

*Corresponding author: Paolo Ruggero Errante, Associate Researcher, Laboratory of Autonomic and Cardiovascular Pharmacology, Department of Pharmacology, UNIFESP, São Paulo-SP, Brazil

\section{ARTICLE INFO}

Received: 㗀 January 23, 2021

Published: 櫘 February 05, 2021

Citation: Paolo Ruggero Errante, Afonso Caricati Neto. Resveratrol and Colorectal Cancer: Focus In vitro, In vivo and Clinical Assays. Biomed J Sci \& Tech Res 33(4)2021. BJSTR. MS.ID.005439.

Keywords: Resveratrol; Natural Compound; Cancer; Colorectal Cancer; Cancer Prevention

\begin{abstract}
Resveratrol is a natural non-flavonoid polyphenol present in different plants such as grapes, peanuts, soybeans and berries, which has beneficial effects on humans due to its anti-inflammatory, antioxidant, neuroprotective, cardioprotective and cancer prevention action. Since the effects of resveratrol in vitro on different tumors are significant, its application in the prevention of colorectal cancer can have a positive impact, since resveratrol can be consumed by eating natural foods. However, its effects in experimental models using chemical carcinogens and in clinical trials with humans in the prevention of colorectal cancer have been shown to be inconsistent, largely due to its low aqueous solubility and bioavailability. To overcome these problems, new formulations containing resveratrol have been used to promote increased solubility, bioavailability and therapeutic effect in cancer prevention.
\end{abstract}

Abbreviations: NF-kB: Nuclear Factor kappa B; VEGF: Vascular Endothelial Growth Factor; EGFR: Epidermal Growth Factor Receptor; FGF-2: Fibroblast Growth Factor 2; TGF- $\beta$ : Transforming Growth Factor Beta; EMT: Epithelial Mesenchymal Transition; F344: Fisher 344; IGF 1: Insuline-Like Growth Factor I; IGFBP 3: Insulin-Like Growth Factor-Binding Protein-3

\section{Mini Review}

Resveratrol (3,40,5-trihydroxy-trans-stilbene) is a natural stilbene and non-flavonoid polyphenol present in more of 70 plants species, including peanuts (Arachis hypogaea), Japanese knotweed (Fallopia japonica), grape vine (Vitis vinifera) and foods such as wine, soy, Itadori tea, and red fruits. Resveratrol is a natural compound whose use has been described in the treatment and prevention of different diseases such as inflammatory, cardiovascular, neurological disease and cancer [1]. Resveratrol has in vitro cytotoxic effects against lymphoid and myeloid tumors, breast, skin, cervix, ovary, stomach, prostate, liver, pancreas, thyroid and colon tumors [2]. Its antitumor effects have been associated with different mechanisms, such as interruption of cell cycle and induced of apoptosis; inhibition of nitric oxide synthase expression; antioxidant effect with inhibition of lipid peroxidation and DNA damage; inhibition of the cyclooxygenase pathway of arachidonic acid metabolism; and procarcinogen bioactivation and carcinogen detoxification [3].
Resveratrol alters the activity of cyclin-dependent kinases and the cell cycle in the G0/G1 phase, and activation of the p53-dependent pathway, limiting the tumor growth [4,5]; and inhibits anti-apoptotic proteins of Bcl-2 family and activates proapoptotic proteins like Bad, Bak, Bax, PUMA, Noxa and Bim [6]. Resveratrol promotes inhibition of signal transducer and activator of transcription 3 (STAT3) and nuclear factor kappa B (NF-kB), nuclear transcription factors activated by acetylation and/or phosphorylation that's increased proliferative, invasive, angiogenic and metastatic activity [7]; have an inhibitory role on the expression of metalloproteinase-2 and metalloproteinase-9 (MMP-2 and MMP9) and angiogenic molecules such as vascular endothelial growth factor (VEGF), epidermal growth factor receptor (EGFR) and fibroblast growth factor 2 (FGF-2) [8]; and suppresses signaling associated with transforming growth factor beta (TGF- $\beta$ )-mediated epithelial mesenchymal transition (EMT) [9]. 


\section{Colorectal Cancer}

Approximately 90 to $95 \%$ of cancer cases described in humans are related to lifestyle, diet, pollution and obesity [10], where colorectal cancer corresponds to the third most frequent cancer in men, behind prostate and lung cancer. Colorectal cancer has an important relationship with lifestyle and diet rich in red meat and processed meat, low content of non-absorbable vegetable fibers, high content of refined carbohydrates, alcoholism and smoking [11]. Colorectal cancer has a peak incidence between 60 and 70 years of age, with worldwide distribution and greater incidence in the United States, Canada, Australia, New Zealand, Denmark and Sweden [12,13]. Because determinates plants (for example grape) and their derivatives have been used as complementary therapy in the treatment and prevention of several types of cancer, there is great potential in the use of plants containing resveratrol in the prevention of colorectal cancer.

The antitumor effect of resveratrol has been described in vitro in different colorectal cancer cell lines, such as HT-29 [14], LoVo [15], oxaliplatin-resistant colorectal cancer cells (HCT116/L-OHP) [16], human colorectal cancer stem cells [17], parental CRC cell lines (HCT116, SW480) and their isogenic 5-FU-chemoresistant clones (HCT116R, SW480R) [18] and cisplatin-resistant colorectal cancer cells HCT-116 [19]. In the process of colorectal carcinogenesis, there are two distinct pathways, the APC/ $\beta$-catenin pathway (adenoma-carcinoma sequence) and the mismatch repair pathway (microsatellite instability). In the first pathway, localized epithelial proliferation occurs and the formation of adenomas that become dysplastic and later turn into cancer. In the second pathway, genetic lesions occur in the DNA genes of mismatched repair (MSH2, MSH6, MLH1, PMS1 and PMS2) causing hereditary nonpolyposis colorectal carcinoma [20,21]. To study the role of resveratrol in different mechanisms of colorectal carcinogenesis, Fisher 344 (F344) rats previously treated with resveratrol demonstrated a minor number of aberrant cryptic foci in colon mucosa after chemical carcinogenesis, with increase in the expression of Bax protein [22]

Using Wistar rats was observed the influence of resveratrol in the inhibition on cyclooxygenase- 2 synthesis, important to cellular proliferation, inhibition of apoptosis and angiogenesis in colorectal genesis. The preventive use of resveratrol demonstrated a low expression of aberrant crypt foci, lower activity of cyclooxygenase-2 and increased expression of cleaved caspase-3 [23,24]. The diminish of aberrant crypt foci and depletion of mucin foci (a risk factor to development of colon carcinoma) was observed in Sprage-Dawley rats treated with resveratrol [25]. The prophylactic use of resveratrol in $\mathrm{C} 57 \mathrm{BL} / 6 \mathrm{~J}-\mathrm{Apc}^{\mathrm{min} / \mathrm{C}}$ mice (heterozygotes mice susceptible to spontaneous intestinal adenoma formation) demonstrated a reduction in the expression of D1 and D2 cyclins and dysplastic cells in intestinal mucosa [26] or prostaglandin $E_{2}$ levels in intestinal cells [27]. Epidemiological studies in humans demonstrated that consumption of grape was associated with lower risk development of different kinds of cancer [28], including breast [29] and head and neck carcinoma [30].

In patients with colorectal cancer, the oral use of resveratrol was demonstrated a lower diminish on proliferative cancer cell activity [31]; moderate decrease in the Wnt/beta-catenin pathway in the intestinal crypt floor, critical pathway to maintenance of stem cells, and involvement in development of colorectal cancer [32]; relative increase of apoptosis on metastatic cells [33]; and reduction of plasma levels of insuline-like growth factor I (IGF1) and binding to insulin-like growth factor-binding protein-3 (IGFBP3), that regulate cancer progression and metastasis [34]. These limited and unsatisfactory results, in addition to the publication of a study that did not describe any beneficial effect of resveratrol on mortality associated with cancer [35], raised doubts about its real benefits in the face of cancer. These results may be associated with different types of study, tumor models and dose of resveratrol. Resveratrol is an extremely photosensitive compound with low chemical stability, low aqueous solubility and bioavailability, leading to a plasma halflife of 8 to 14 minutes, where the primary molecule is metabolized and converted into other secondary compounds with a half-life of 9.2 hours, such as sulfate conjugate, leading to a low therapeutic potency [36].

\section{New Formulations of Resveratrol}

Because the low therapeutic power, new formulations of resveratrol were produced with objective to obtained greater bioavailability, aqueous solubility, pharmacokinetic profile, antioxidant activity and antitumor activity [37], such in the production solid lipid nanoparticles [38], mitochondrial targeting resveratrol liposomes [39], resveratrol conjugated gold nanoparticles [40], resveratrol with methylated- $\beta$-cyclodextrin [41], colloidal mesoporous silica nanoparticles [42], resveratrol loaded into PEGylated liposomes (RES-L) with the liposome surface modified with transferrin moieties (Tf-RES-L) [43] and folate-conjugate human serum albumin-encapsulated resveratrol nanoparticles (FA-HSA-RESNPs) [44].

\section{Discussion}

Resveratrol has significant antitumor activity in vitro due to its ability to promote decreased prostaglandin $\mathrm{E}_{2}$ synthesis; diminish of oxidative stress; bioactivation of procarcinogens and detoxification of carcinogens; and control of proliferation, invasion, angiogenesis and tumor metastasis. However, the results obtained through the use of experimental models induced by chemical carcinogens and the clinical trials in humans used in the prevention of colorectal cancer are limited and low significant in function of different factors, including low chemical stability, solubility and bioavailability of resveratrol. For increased bioavailability and modulation of resveratrol metabolism, new formulations and bioavailable analogs have been produced in search of new therapeutic agents for cancer prevention. 


\section{Conclusion}

Optimizing the chemical stability and solubility of resveratrol can make it have great potential in preventing colorectal cancer.

\section{Conflict of Interest}

The authors declare that there is no conflict of interest.

\section{References}

1. Tian B, Liu J (2020) Resveratrol: a review of plant sources, synthesis, stability, modification and food application. J Sci Food Agric 100(4): 1392-1404.

2. Rauf A, Imran M, Butt MS, Nadeem M, Peters DG, et al. (2018) Resveratrol as an anti-cancer agent: A review. Crit Rev Food Sci Nutri 58(9): 14281447.

3. Carter LG, D’Orazio JÁ, Pearson KJ (2014) Resveratrol and cancer: focus on in vivo evidence. Endocr Relat Cancer 21(3): R209-R225.

4. Ge J, Liu Y, Li Q, Guo X, Gu L, et al. (2013) Resveratrol induces apoptosis and autophagy in T-cell acute lymphoblastic leukemia cells by inhibiting Akt/mTOR and activating p38-MAPK. Biomed Environ Sci 26(11): 902911.

5. Diaz Gerevini GT, Repossi G, Dain A, Tarres MC, Das UM, et al. (2016) Nutrition 32(2): 174-178.

6. Aziz MH, Nihal M, Fu VX, Jarrard DF, Ahmad N (2006) Resveratrol-caused apoptosis of human prostate carcinoma LNCaP cells is mediated via modulation of phosphatidylinositol 3'-kinase/Akt pathway and Bcl-2 family proteins. Mol Cancer Ther 5(5):1335-1341.

7. Bhardwaj A, Sethi G, Vadhan Raj S, Bueso Ramos C, Takada Y, et al. (2007) Resveratrol inhibits proliferation, induces apoptosis, and overcomes chemoresistance through down-regulation of STAT3 and nuclear factorkappa B-regulated antiapoptotic and cell survival gene products in human multiple myeloma cells. Blood 109(6): 2293-2302.

8. Castino R, Pucer A, Veneroni R, Morani F, Peracchio C, et al. (2011) Resveratrol reduces the invasive growth and promotes the acquisition of a long-lasting differentiated phenotype in human glioblastoma cells. J Agric Food Chem 59(8): 4264-4272.

9. Vergara D, Valente CM, Tinelli A, Siciliano C, Lorusso V, et al. (2011) Resveratrol inhibits the epidermal growth factor-induced epithelial mesenchymal transition in MCF-7 cells. Cancer Lett 310(1): 1-8.

10. Irigaray P, Newby JA, Clapp R, Hardell L, Howard V, et al. (2007) Lifestylerelated factors and environmental agents causing cancer an overview. Biomed Pharmacother 61(10): 640-658.

11. Thanikachalam K, Khan G (2019) Colorectal cancer and nutrition. Nutrients 11(1): 164

12. Arnold M, Sierra MS, Laversanne M, Soerjomataram I, Jemal A, et al. (2017) Global patterns and trends in Colorectal incidence and mortality. Gut 66(4): 683-691.

13. Dekker E, Tanis PJ, Vleugels JLA, Kasi PM, Wallace MB (2019) Colorectal cancer. Lancet 394(10207): 1467-1480.

14. Schroeter A, Marko D (2014) Resveratrol modulates the topoisomerase inhibitory potential of doxorubicin in human colon carcinoma cells. Molecules 19(12): 20054-20072.

15. Ji Q Liu X, Han Z, Zhou L, Sui H, et al. (2015) Resveratrol suppresses epithelial-to-mesenchymal transition in colorectal cancer through TGF-ß1/Smads signaling pathway mediated Snail/E-cadherin expression. BMC Cancer 15: 97.

16. Wang Z, Zhang L, Ni Z, Gao H, Cheng H, et al. (2015) Resveratrol induces AMPK-dependent MDR1 inhibition in colorectal cancer HCT116/L-OHP cells by preventing activation of NF-kB signaling and suppressing cAMPresponsive element transcriptional activity. Tumor Biol 36(12): 94999510.
17. Yang J, Liu J, Lyu X, Fei S (2015) Resveratrol inhibits cell proliferation and up-regulates MICA/B expression in human colon cancer stem cells. Xi Bao Yu Fen Zi Mian Yi Xue Za Zhi 31(7): 889-893.

18. Buhrmann C, Shavan P, Kraehe P, Popper B, Goel A, et al. (2015) Resveratrol induces chemosensitization to 5-fluorouracil through up-regulation of intercellular junctions, epithelial-to-mesenchymal transition and apoptosis in colorectal cancer. Biochem Pharmacol 98(1): 51-68.

19. Osman AM, Al Malki HS, Al Harthi SE, El Hanafy AA, Elashmaoui H, et al. (2015) Modulation role of resveratrol on cytotoxic activity of cisplatin, sensitization and modification of cisplatin resistance in colorectal cancer cells. Mol Med Rep 12(1): 1368-1374.

20. Markowitz SD, Bertagnolli MM (2009) Molecular origins of cancer: molecular basis of colorectal cancer. N Engl J Med 361(25): 2449-2460.

21. De Rosa M, Pace U, Rega D, Costabile V, Duraturo F, et al. (2015) Genetics, diagnosis and management of colorectal cancer (Review). Oncol Rep 34(3): 1087-1096.

22. Tessitore L, Davit A, Sarotto I, Caderni G (2000) Resveratrol depresses the growth of colorectal aberrant crypt foci by affecting Bax and p21(CIP) expression. Carcinogenesis 21(8): 1619-1622.

23. Sengottuvelan M, Nalini N (2006) Dietary suplementation of resveratrol suppress colonic tumor incidence in 1,2-dimethylhydrazine-treated rats by modulating biotransforming enzymes and aberrant crypt foci development. Br J Nutr 96(1): 145-153.

24. Sengottuvelan M, Deeptha K, Nalini N (2009) Influence of dietary resveratrol on early and late molecular markers of 1,2-dimethylhydrazineinduced colon carcinogenesis. Nutrition 25(11-12): 1169-1176.

25. Alfaras I, Juan ME, Planas JM (2010) Tans-resveratrol reduces precancerous colonic lesions in dimethylhydrazine-treated rats. J Agric Food Chem 58(13): 8104-8110.

26. Schneider Y, Duranton B, Gossé F, Schleiffer R, Seiler N, et al. (2001) Resveratrol inhibits intestinal tumorigenesis and modulates hostdefense-related gene expression in an animal model of human familial adenomatous polyposis. Nutr Cancer 39(1): 102-107.

27. Sale S, Tunstall RG, Ruparelia KC, Potter GA, Steward WP, et al. (2005) Comparison of the effects of the chemopreventive agent resveratrol and its synthetic analog trans 3,4,5,4'-tetramethoxystilbene (DMU-212) on adenoma development in the Apc (Min+) mouse and cyclooxygenase-2 in human-derived colon cancer cells. Int J Cancer 115(2): 194-201.

28. Renaud SC, Guéguen R, Schenker J, d’Houtaud A (1998) Alcohol and mortality in middle-aged men from eastern France. Epidemiology $9(2)$ 184-188.

29. Levi F, Pasche C, Lucchini F, Ghidoni R, Ferraroni M, et al. (2005) Resveratrol and breast cancer risk. Eur J Cancer 14(2): 139-142.

30. Salvatore Benito A, Valero Zanuy MA, Alarza Cano M, Ruiz Alonso A, Alda Bravo I, et al. (2019) Adherence to Mediterranean diet: a comparison of patients with head and neck cancer and healthy population. Endocrinol Diabetes Nutr 66(7): 417-424.

31. Patel KR, Brown VA, Jones DJ, Britton RG, Hemingway D, et al. (2010) Clinical pharmacology of resveratrol and its metabolites in colorectal cancer patients. Cancer Res 70(19): 7392-7399.

32. Nguyen AV, Martinez M, Stamos MJ, Moyer MP, Planutis K, et al. (2009) Results of a phase I pilot clinical trial examining the effect of plantderived resveratrol and grape powder on Wnt pathway target gene expression in colonic mucosa and colon cancer. Cancer Manag Res 1: 25-37.

33. Howells LM, Berry DP, Elliot PJ, Jacobson EW, Hoffmann E, et al. (2011) Phase I randomized, double-blind pilot study of micronized resveratrol (SRT501) in patients with hepatic metastases-safety, pharmacokinetics, and pharmacodynamics. Cancer Prev Res (Phila) 4(9): 1419-1425.

34. Brown VA, Patel KR, Viskaduraki M, Crowell JA, Perloff M, et al. (2010) Repeat dose study of the cancer chemopreventive agent resveratrol in 
healthy volunteers: safety, pharmacokinetics, and effect on the insulinlike growth factor axis. Cancer Res 70(22): 9003-9011.

35. Semba RD, Ferrucci L, Bartali B, Urpí Sarda M, Zamora Ros R, et al. (2014) Resveratrol levels and all-cause mortality in older Community-dwelling adults. JAMA Inter Med 174(7): 1077-1084.

36. Bauer JA, Siclair DA (2006) Therapeutic potential of resveratrol: the in vivo evidence. Nat Rev Drug Discov 5(6): 493-506.

37. Summerlin N, Soo E, Thakur S, Qu Z, Jambhrunkar S, et al. (2015) Resveratrol nanoformulations: challenges and opportunities. Int J Pharm 479(2): 282-290.

38. Teskac K, Kristl J (2010) The evidence for solid nanoparticles mediated cell uptake of resveratrol. Int J Pharm 390(1): 61-69.

39. Wang XX, Li YB, Yao HJ, Ju RJ, Zhang Y, et al. (2011) The use of mitochondrial targeting resveratrol liposomes modified with a dequalinium polyethylene glycol-distearoylphosphatidyl ethanolamine conjugate to induce apoptosis in resistant lung cancer cells. Biomaterials 32(24): 5673-5687.

\section{ISSN: 2574-1241}

DOI: $10.26717 /$ BJSTR.2021.33.005439

Paolo Ruggero Errante. Biomed J Sci \& Tech Res

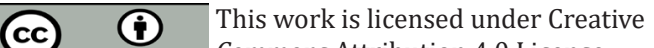

Submission Link: https://biomedres.us/submit-manuscript.php
40. Kumar CG, Poornachandra Y, Mamidyala SK (2014) Green synthesis of bacterial gold nanoparticles conjugated to resveratrol as delivery vehicles. Colloids Surf B Biointerfaces 123: 311-317.

41. Duarte A, Martinho A, Luis A, Figueiras A, Oleastro M, et al. (2015) Resveratrol encapsulation with methyl-b-cyclodextrin for antibacterial and antioxidant delivery application. LWT-Food Sci Technol 63(2): 1254-1260.

42. Summerlin N, Qu Z, Pujara N, Sheng Y, Jambhrunkar S, et al. (2016) Colloidal mesoporous silica nanoparticles enhance the biological activity of resveratrol. Colloids Surf B Biointerfaces 144: 1-7.

43. Jhaveri A, Deshpande P, Pattni B, Torchilin V (2018) Transferrin-targeted, resveratrol-loaded liposomes for the treatment of glioblastoma. J Control Release 277: 89-101.

44. Lian B, Wu M, Feng Z, Deng Y, Zhong C, et al. (2019) Folate-conjugate human serum albumin-encapsulated resveratrol nanoparticles: preparation, characterization, bioavailability and targeting of liver tumors. Artif Cells Nanomed Biotechnol 47(1): 154-165.

$\begin{array}{ll}\text { BIOMEDICAL } & \text { Assets of Publishing with us } \\ \text { RESEARCHES } & \text { - Global archiving of articles } \\ \text { - Immediate, unrestricted online access } & \text { - Rigorous Peer Review Process } \\ & \text { - Authors Retain Copyrights } \\ \end{array}$

